\title{
NATURALEZA JURIDICA DE LA RELACION ENTRE LOS REPARTIDORES Y MENSAJEROS Y LAS EMPRESAS DE TRANSPORTE: ¿CONTRATO LABORAL O MERCANTIL?
}

\author{
Javier Rodríguez Gutiérrez
}

\section{Introducción: planteamiento del problema}

Existen muchas relaciones jurídicas que se encuentran a medio camino entre el derecho laboral y el mercantil —en las llamadas por la doctrina «zonas grises o fronterizas» ${ }^{1}$ - , pero entre ellas sin duda una de las más problemáticas es la que une a las empresas dedicadas al transporte y reparto de mercancías, con los propios transportistas y repartidores. La cuestión acerca de si ésta reúne las condiciones exigidas por el art. 1 del Estatuto de los Trabajadores como configuradoras de toda relación laboral, o si, por el contrario, debe encuadrarse en el marco de un contrato mercantil, ha sido, y aun hoy en día sigue siendo, uno de los grandes caballos de batalla sobre los que hay que moverse con suma prudencia, puesto que no existe una doctrina con carácter general. La jurisprudencia ha pasado por varias fases, que en definitiva se pueden resumir en un antes y un después de la famosa Sentencia de los mensajeros $^{2}$, tal y como ha sido denominada por la doctrina científica. La Disposición Final Séptima de la Ley 11/1994 de 19 de mayo, que adiciona un nuevo apartado 9) al artículo 1.3. ${ }^{\circ}$ del Estatuto de los Trabajadores, ha venido a poner algo de luz a tan oscuro y complejo debate, pero desde luego no viene a solucionar, ni mucho menos, todos los problemas que se plantean para delimitar la naturaleza de esta clase de relaciones.

1 VALDÉs DAL-RE, Fernando, «Ley y Jurisprudencia en la delimitación del ámbito del ordenamiento laboral: un diálogo en divergencia», Relaciones Laborales, 1994 (Il), págs. 31 y ss.

2 Sentencia del T.S. de 26 de febrero de 1996. 
Lo cierto es que la determinación de si estamos ante una relación laboral o una extralaboral, debe ser examinada casuísticamente, puesto que es en cada caso concreto donde debe comprobarse si se reúnen las características necesarias para entender que existe relación laboral, o no. La necesidad de aportar un vehículo propio, el sometimiento a horario y jornada, la jerarquía, la dependencia, la ajenidad, la subordinación, la exclusividad en la prestación del servicio para una única empresa, el carácter personalísimo de la prestación del servicio, el sometimiento al ámbito de organización y dirección del empresario, la percepción de una retribución fija mensual, etc., son las notas que habrán de ser examinadas para poder dar una respuesta adecuada a la cuestión que aquí se plantea.

Por otra parte, la realidad es que en muchos casos el hecho de que el repartidor o mensajero sea autónomo se debe en cierta manera a una «recomendación» de la propia empresa transportista, que para evitar las cargas sociales de contratar a un trabajador, le ofrece trabajo a cambio de que éste se dé de alta en el Régimen Especial de Trabajadores Autónomos de la Seguridad Social (RETA), y en el Impuesto de Actividades Económicas (IAE), aunque en la práctica preste sus servicios únicamente en dicha empresa con carácter permanente, y con todas las características propias de una relación laboral. La Inspección de Trabajo, conocedora de los fraudes que se producen en este sector, comenzó a dar de alta de oficio a esta clase de trabajadores, generalizando así las maniobras defraudadoras que eran puestas en práctica por unos pocos, y afectando a personas que de hecho eran autónomos, y que deseaban seguir siéndolo. Es evidente que, si bien es sabido que la relación laboral se configura al margen de los deseos de las partes contratantes, es decir, que por mucho que para empresa y trabajador la relación sea mercantil, si reúne las características propias de un contrato laboral, tendrá tal consideración, sin embargo, también debe respetarse la libertad de una persona, propietario de un vehículo, para decidir dedicarse profesionalmente al transporte de mercancías, como empresario individual, sin mantener ninguna vinculación laboral con las empresas de transporte que la contratan para la realización efectiva del mismo.

Vamos a analizar a continuación la jurisprudencia existente en la materia, con el giro operado tras la Sentencia de los mensajeros, para posteriormente estudiar la nueva regulación existente sobre la materia con la aparición del artículo 1.3. ${ }^{\circ} \mathrm{g}$ ) del Estatuto de los Trabajadores, y finalmente destacar las características que pueden decantar en el caso concreto la decisión sobre la naturaleza jurídica de tan controvertida relación. 


\section{Análisis jurisprudencial}

\subsection{La situación antes de la Sentencia de 26 de febrero de 1986}

Dos relaciones jurídicas se producen en las situaciones que estamos analizando: la primera entre la empresa y el cliente o destinatario en su caso de la mercancía, quien contrata a aquella para que efectúe el transporte de la misma, y la segunda entre la empresa de transporte y el concreto repartidor, distribuidor, mensajero o transportista que realiza el servicio. Es esta segunda relación la que nos interesa, y en ella es evidente que la empresa puede tener sus propios empleados en plantilla que realicen los transportes, o puede acudir a transportistas autónomos que los desarrollarán aportando su propio vehículo. La duda y la razón de ser de todo el problema reside en determinar si el transportista puede ser considerado como un auténtico empresario mercantil, o si por el contrario ello es una mera fachada que enmascara una auténtica relación laboral. Como decíamos antes, a este interrogante sólo se puede responder examinando las circunstancias que concurren en cada caso, puesto que si bien a todos nos parecería normal que una persona que ha adquirido un camión y se dedica profesionalmente a transportar mercancías de diversas empresas movido por un ánimo de lucro, debe ser considerada un auténtico empresario, sin embargo probablemente no pensaríamos lo mismo de un joven que con la ayuda de su modesto ciclomotor reparte los productos de una pastelería a sus clientes. Son dos ejemplos extremos que denotan claramente las diferencias existentes, pero entonces la cuestión que se plantea es ¿cuál debe ser el factor determinante que delimite la frontera entre una y otra situación? ${ }^{3}$.

Tradicionalmente la jurisprudencia se ha venido manifestando en contra de la existencia de un vínculo laboral entre el transportista y la empresa, de forma que el orden jurisdiccional social se declaraba sistemáticamente incompetente para resolver las cuestiones emanadas de la relación entre ambos, por entender que se trataba de una relación de carácter mercantil. Varios factores justificaban esta postura:

En primer lugar, era requisito indispensable que el vehículo fuese aportado por el repartidor o mensajero, y éste fuera su propietario, o por lo menos ostentara un poder de disposición total sobre el mismo. Evidentemente, si el vehículo pertenecía a la empresa, resultaba en todo

3 Una síntesis de la evolución jurisprudencial puede encontrarse en LuJÁN AlCARAz, José, Repartidores y mensajeros: ¿contrato laboral o de transporte?, Colección Jurisprudencia práctica, Madrid, Tecnos, 1990. 
punto absurdo considerar a aquel como empresario suscriptor de un contrato mercantil, puesto que careció del elemento indispensable y mínimo necesario para ejercer su trabajo. Lo mismo sucedía en el caso de que el vehículo llevara publicidad de la empresa ${ }^{4}$.

En segundo lugar el carácter no personalísimo de las obligaciones emanadas del contrato de transporte, frente al carácter intuitu personae propio de toda relación laboral. Efectivamente, la índole personal de la prestación del trabajador es una característica fundamental para la existencia de un contrato laboral: el contratado es quien debe prestar el servicio personalmente, y no otra persona en su lugar. En cambio, en el contrato de transporte lo verdaderamente determinante es que se cumpla la obligación de entrega de la mercancía, sin que sea relevante si ello lo realiza personalmente la persona contratada, o bien otra a su servicio. De esta forma, en los casos en que faltaba el carácter intuitu personae de la prestación, el Tribunal Supremo excluía por principio la posibilidad de estar en presencia de una relación laboral ${ }^{5}$, aunque matizando que no es suficiente con establecer en un contrato mercantil una cláusula que posibilite la sustitución del conductor o transportista, si dicha cláusula está tan condicionada y sometida a la voluntad de la empresa que en la práctica no puede ser tenida como una facultad de aquel ${ }^{6}$.

Un tercer aspecto relevante para avalar la no laboralidad de la relación es el referente a la autonomía o independencia del transportista, respecto al ámbito de dirección y organización del empresario. Es decir, si aquel no queda sometido a dicho ámbito, de forma que no dispone de horario de entrada y salida, de jornada laboral, de retribución fija mensual, etc., no se podría considerar empleado, sino un mero colaborador mercantil, que realiza los servicios en virtud de un contrato de transporte que le une con la empresa, pero que no le ata a la misma en régimen de exclusividad, sino que él, como empresario mercantil, puede contratar sus servicios con diversas entidades o personas físicas, sin

4 Así se indica por ejemplo y entre otras muchas, en la Sentencia del Tribunal Supremo de 2 de octubre de 1971, en la que a pesar de haber arrendado la empresa un camión al repartidor, éste tenía limitado su poder de disposición, puesto que venía obligado a utilizarlo sólo en el servicio de la propietaria y en el lugar, tiempo y forma sujetos a la decisión de ésta, que se extendió a lo concerniente al seguro, abastecimiento y reparaciones del vehículo e incluso a su aspecto externo, por deber ir pintado con los colores y nombre de la empresa.

5 Así sucede «ad exemplum», en la Sentencia de 26 de febrero de 1974, y en la de fecha 20 de septiembre de 1984, en la que el transportista podía o no acudir a prestar el servicio, según tuviera por conveniente. Lo mismo en las Sentencias de 18 de noviembre de 1976 y 23 de abril de 1983.

6 Vid. Sentencia del Tribunal Supremo de 2 de octubre de 1971, ya citada. 
ninguna limitación. Si no hay potestad de mando y obligación de dependencia, no existe relación laboral ${ }^{7}$. Ahora bien: en este punto hay que tener en cuenta que la mera relación mercantil también requiere una cierta dependencia, que no debe ser interpretada como ajenidad, es decir, el transportista puede tener que asumir concretas obligaciones derivadas de su contrato mercantil, como la existencia de un determinado horario de recogida y entrega, o una serie de instrucciones por ejemplo en cuanto a rutas a seguir, pero ello no es óbice para entender que existe una autonomía funcional y material ${ }^{8}$.

Otra característica relevante es la relativa a la asunción por parte del transportista del riesgo de la explotación. Si quien transporta la mercancía fuese un asalariado de la empresa de reparto, sería ésta quien respondería de la suerte de la misma. Sin embargo, en caso de que se trate de un transportista profesional, lógicamente es él directamente el responsable de que los bienes transportados lleguen a su destino en perfecto estado, aunque el cliente concreto se dirigirá por supuesto contra la empresa de transporte con la que contrató el mismo.

Por último hay que destacar el ánimo de lucro que mueve al transportista. Mientras que el personal asalariado percibe una contraprestación fija mensual, el transportista autónomo está movido por una intención lucrativa, por un deseo empresarial de obtener el máximo rendimiento, y por ende el máximo beneficio de su explotación, que en este caso es su vehículo. Utilizando el repartidor un medio de locomoción propio, y siendo todos los gastos de manutención del mismo de su cuenta, entiende la jurisprudencia que la retribución es una contraprestación de todo un conjunto de aportaciones ${ }^{9}$. Sucede en este punto que en ciertos casos puede resultar complicado detectar cuándo nos encontramos ante una intención lucrativa que excede de la mera percepción de un sueldo mensual.

\subsection{La Sentencia del T.S. de 26 de febrero de 1986}

La conocida como «Sentencia de los mensajeros» opera una importante modificación en la línea jurisprudencial que hasta ese momento se había venido manteniendo, y que se ha recogido en el epígrafe anterior. Efectivamente, esta resolución va a integrar a los mensajeros en

\footnotetext{
7 Sentencia del Tribunal Supremo de 20 de septiembre de 1984.

8 Sentencias del Tribunal Supremo de 17 de marzo y 22 de octubre de 1983, 16 de julio y 20 de septiembre de 1984, 8 y 29 de octubre de 1985, 15 de septiembre de 1986, etc.

9 Sentencias del Tribunal Supremo de 29 de octubre de 1985 y 27 de enero de 1986 entre otras.
} 
el ámbito laboral, considerándolos asalariados de las empresas de transporte para las que prestan sus servicios ${ }^{10}$.

Recoge la referida sentencia el supuesto típico una empresa de transporte de paquetería, la cual dispone de una serie de mensajeros que efectúan los servicios a través de unas motocicletas de su propiedad, cobran una tanto por viaje, sin relación con el precio del transporte que paga el cliente, asumen los gastos de combustible y manutención del vehículo, portan publicidad en el mismo y en su vestimenta, y sólo responden del deterioro de la mercancía si ha existido negligencia en el transporte; deben llamar todos los días telefónicamente a la empresa para saber si tienen repartos que realizar. Estos mensajeros tienen suscrito con la empresa un contrato de transporte, en el que se establece que no quedarán sometidos a horario ni a jornada, que no tendrán dedicación exclusiva a la empresa, que podrán efectuar el trabajo por sí mismos, o a través de otras personas retribuidas por ellos, y que serán autónomos, debiendo cumplir con sus obligaciones tributarias y de cotización, en tal sentido.

Pues bien: el Tribunal Supremo encuentra en este caso todas y cada una de las características propias de la relación laboral:

- Carácter voluntario y retribuido del servicio.

- La ajenidad: el trabajador no asume ni el riesgo ni el beneficio del contrato de transporte firmado entre la empresa y el cliente, no interviene en la fijación del precio del mismo, y su retribución no depende del resultado.

- La dependencia: el trabajador porta publicidad de la empresa en su vestimenta y en su vehículo, queda obligado a llamar todos los días a la empresa para recibir las órdenes de trabajo, y puede ser penalizado si no lo hace. El hecho de que no asista al trabajo todos los días no desnaturaliza la relación laboral según el Tribunal Supremo, puesto que se desconocen las causas de la inasistencia, pudiendo deberse simplemente al deseo de la empresa de desvirtuar la laboralidad de la relación. La falta de exclusividad tampoco es un dato que desnaturalice un contrato de trabajo.

-El carácter personal de la prestación: señala el T.S. en este punto que el hecho de que en el contrato de transporte firmado se recoja la posibilidad de que el mensajero podría ser sustituido por otra persona, no es sino un nuevo intento de la empresa de desvirtuar

10 Un estudio exhaustivo sobre esta Sentencia puede encontrarse en RIVERO LAMAS, Juan y GARCía Blasco, Juan, «Transporte de cosas y mercancías y contrato de trabajo», Relaciones Laborales, 1987 (II), págs. 507-536. 
la verdadera naturaleza laboral del contrato, y prueba de ello es que en el caso concreto que nos ocupa nunca se produjo en la práctica esta sustitución.

Lo cierto es que, a mi modo de ver, la interpretación que realiza el Tribunal en algunos de estos aspectos es bastante forzada, especialmente en el punto relativo al carácter «intuitu personae» de la prestación. Efectivamente, el hecho de que durante el transcurso de la relación entre la empresa y los mensajeros nunca se hubiera utilizado la posibilidad de sustitución, no parece suficiente para deducir que esa cláusula establecida en el contrato tiene como única misión desvirtuar la naturaleza del mismo, y derivarlo hacia el ámbito civil. Se trata de una acusación de fraude contra la empresa, que no parece que tenga a simple vista sólidos fundamentos en los que apoyarse; más bien nos encontramos ante una mera presunción. La misma argumentación podría sostenerse con respecto a la dependencia, toda vez que el Tribunal Supremo aprecia esta característica en el hecho de que los trabajadores porten publicidad de la empresa, y de que deban llamar diariamente a la empresa con objeto de averiguar si hay trabajo para ellos. Se trata de meros indicios que no justifican plenamente que el mensajero se encuentre bajo el poder de dirección del empresario, máxime cuando está acreditado que no existe jornada, ni horario laboral, ni exclusividad en la prestación de los servicios.

Por otra parte, existió un dato de gran relevancia: los vehículos mediante los cuales se ejecutaban los servicios eran propiedad de los mensajeros. Hasta ese momento, la jurisprudencia dominante señalaba esta característica como fundamental a la hora de dilucidar si una relación era laboral o civil: el hecho de que el vehículo fuera propiedad del mensajero inclinaba la balanza decisivamente hacia la segunda posibilidad. Sin embargo, el Tribunal Supremo en esta Sentencia matiza este punto de la siguiente forma: cuando se señala que en el caso de que quien preste el servicio utilice medios propios estamos ante un contrato de carácter mercantil, se está considerando el vehículo como el elemento esencial del contrato, y ello puede tener lugar en los casos de camiones o furgonetas de reparto que han requerido una fuerte inversión económica, a la que su propietario pretende sacarle el máximo rendimiento posible, pero no en los casos como el que nos ocupa, de pequeñas motocicletas. Estas, dado su menor coste inicial y de mantenimiento, y difusión de uso, no pueden considerarse elemento esencial del contrato, sino secundario de la actividad personal, de forma que es esa aportación personal del mensajero la que se erige en la actividad principal y razón de ser de la empresa. 
Por tanto, parece que la inversión económica y la difusión de uso del vehículo son los rasgos claves para determinar en estos casos si estamos ante un contrato laboral o mercantil. Se entiende que un vehículo modesto y de bajo coste, como es una motocicleta, no puede ser el soporte de una explotación económica, y su titular no puede considerarse por ello un empresario. En estos casos, el trabajo del mensajero es la actividad principal de la empresa, siendo el vehículo un mero instrumento.

\subsection{Consecuencias de la «Sentencia de los mensajeros»: un giro en la jurisprudencia ${ }^{11}$}

La referida Sentencia supuso en su día, como decimos, una ruptura con la línea tradicional que habían venido manteniendo tanto el Tribunal Supremo como el hoy extinto Tribunal Central de Trabajo. La duda que se planteaba era si el Tribunal iba a seguir manteniendo esta posición, o si por el contrario se trataba de un caso aislado, o previsto específicamente para los llamados «mensajeros urbanos», que ejercen su actividad con motocicletas, y no iba a afectar al resto de los profesionales que emplean vehículos de mayor capacidad y coste económico. En apoyo de esta última tendencia estaba, por una parte, la influencia de factores sociales, y en particular la presión sindical en búsqueda de protección para estos motoristas que se encontraban en precaria situación, ya que, como hemos señalado anteriormente, en algunos casos eran explotados por las empresas de reparto, que les convencían de la «conveniencia» de convertirse en autónomos, so pena de no darles trabajo en caso contrario; una práctica efectuada, por supuesto, no por todas las empresas, pero que se generalizó en la conciencia tanto de los propios sindicatos como de la Inspección de Trabajo, que comenzó a elevar Actas de Infracción, y de Alta de Oficio para estos trabajadores, sin analizar los casos concretos, y a veces en contra de la propia voluntad del trabajador. Por otra parte, de la propia argumentación esgrimida por el Tribunal en su Sentencia, se puede extraer como criterio principal y diferenciador, el del valor de la inversión económica efectuada por el trabajador, de forma que era lógico pensar que la línea jurisprudencial futura se iba a guiar por dicho criterio.

Efectivamente, en un primer momento así fue: en una de las primeras ocasiones en que el T.S. tiene oportunidad de volver a pronunciarse

\footnotetext{
11 Un estudio inicial sobre este tema puede encontrarse en Pedraja Moreno, Abdón, y VALDÉS DAL-RE, Fernando, «Contrato de trabajo y contrato de transporte, ¿un giro en la jurisprudencia?», Documentación Laboral, 1986, págs. 97-140.
} 
sobre el tema ${ }^{12}$, realiza una firme diferenciación entre el llamado «mensajero», y el transportista profesional, propietario de un vehículo de tonelaje industrial, con licencia fiscal, y que en todo momento figura como titular de una empresa de transporte. Al primero le une con la empresa de reparto una relación de carácter laboral de acuerdo con lo establecido en la Sentencia de 26 de febrero, por mucho que se intente enmascarar a través de la suscripción de un contrato mercantil. Sin embargo, en el segundo caso, el Tribunal entiende que si estamos ante una relación mercantil, en virtud de la cual una persona que tiene la condición de empresario transportista, con Licencia Fiscal y de Alta en el Régimen de Autónomos, y al que mueve un lucro empresarial distinto del puramente laboral, se obliga no tanto a prestar una actividad personal como a obtener un resultado aportando su propio vehículo, siendo de su cuenta los gastos de combustible y mantenimiento del mismo, y no habiéndose pactado un régimen de exclusividad. En estos casos - señala la referida Sentencia-, el hecho de tener establecido un horario en la prestación de la actividad, y deber acatar decisiones sobre la ruta, no supone sino una mera dependencia técnica que no implica su inclusión en el círculo rector de una empresa. De la misma forma, el Tribunal Central de Trabajo también acoge la argumentación del Tribunal Supremo y adopta soluciones acordes a la «Sentencia de los mensajeros» ${ }^{13}$.

A partir de ahí, sin embargo, se va generalizando en la jurisprudencia la laboralidad de la relación entre el repartidor y la empresa de transporte, de forma que deja de tener tanta importancia la inversión económica efectuada en la adquisición del vehículo, y aun en supuestos en los que éste no es una motocicleta, sino una furgoneta o automóvil, cumpliéndose el resto de condiciones necesarias para la existencia de relación laboral, se reconoce ésta. Así sucede en varias sentencias relativas a profesiones como repartidor de prensa ${ }^{14}$, de productos perecede$\operatorname{ros}^{15}$, de libros ${ }^{16}$, etc. La determinación de cuándo el vehículo es un elemento auxiliar, y cuándo lo es principal, se hace sobre la base de criterios como el valor económico, su tamaño, o el coste de su mantenimiento,

12 Sentencia del Tribunal Supremo de 15 de septiembre de 1986.

13 Así por ejemplo, en la Sentencia de 16 de julio de 1986, declaró la existencia de relación laboral entre un motociclista y una empresa de entrega domiciliaria de mercancías por cuenta de terceros, por considerar que en este caso el elemento fundamental del contrato no era el vehículo, sino el trabajo personal del mensajero.

14 Sentencias del Tribunal Supremo de 26 de junio de 1986, 27 de septiembre de 1987, 2 de febrero y 18 de abril de 1988 , entre otras.

15 Sentencias del Tribunal Supremo de 13 de abril y 6 de julio de 1987, 2 de octubre de 1988, etc.

16 Por ejemplo, en la Sentencia del Tribunal Supremo de 15 de septiembre de 1987. 
pero además se utilizan con carácter indiciario otros criterios añadidos, como el método retributivo que se sigue en la empresa para abonar los servicios al repartidor, la dedicación de éste a la empresa, el carácter personal de la prestación de servicios, o la responsabilidad sobre la car$\mathrm{ga}^{17}$. En definitiva, el Tribunal Supremo va consolidando una doctrina según la cual se establecerá el carácter laboral de la relación en aquellos casos en los que concurran las notas de voluntariedad, ajenidad y dependencia, sin que la aportación por el trabajador de un vehículo propio, cuyos gastos asuma, altere la naturaleza del vínculo, cuando de las circunstancias concurrentes resulta que es la prestación de trabajo el elemento predominante de la relación ${ }^{18}$, es decir, cuando del caso concreto se desprende que la aportación del vehículo no tiene la relevancia económica suficiente para convertir su explotación en elemento definidor de la finalidad fundamental del contrato, mientras que la actividad personal del repartidor se revela como predominante ${ }^{19}$. El hecho de que el transportista esté dado de alta en el RETA y en el IAE, son meros datos formales, que por sí solos no son suficientes para definir el carácter del vínculo, si no van acompañados de otras circunstancias que revelen la falta de ajenidad y dependencia propias del contrato de trabajo $^{20}$, la ausencia de subordinación al ámbito organizativo, directivo y disciplinario de la empresa ${ }^{21}$, o bien la ausencia de la nota más típica de éste, como es su carácter «intuitu personae» ${ }^{22}$. Ante una relación sustancialmente laboral, el hecho de introducir en ella elementos artificiales con objeto de descalificarla no la desnaturaliza desde el momento que dichos elementos carezcan de relevancia para la ejecución del contrato ${ }^{23}$.

Lo cierto es que la extensión generalizada de estos criterios podía incluso poner en peligro la figura del pequeño transportista por cuenta propia, por lo que se hacía urgente delimitar de una forma clara la figura del transportista asalariado, para evitar que acabara ocupando todo el espacio de la actividad de porte de mercancías $^{24}$.

17 VALDÉS DAL-RE, Fernando, «Los inciertos criterios de diferenciación jurisprudencial entre los contratos de trabajo y de transporte», Relaciones Laborales, 1992 (II), pág. 61.

18 Así las Sentencias del Tribunal Supremo de 16 de marzo, 28 de abril, 22, 24 y 31 de julio, y 19 de noviembre de 1992.

${ }_{19}$ Entre otras, Sentencias del Tribunal Supremo de 29 de enero y 3 de diciembre de 1991, 25 de mayo de 1993, 19 de junio de 1995 y 12 de abril de 1996.

20 Sentencia del Tribunal Superior de Justicia de Navarra de 14 de noviembre de 1994.

21 Sentencia del Tribunal Superior de Justicia de Aragón de 22 de junio de 1994.

22 Sentencia del Tribunal Superior de Justicia de Navarra de 31 de diciembre de 1994.

23 Sentencia del Tribunal Supremo de 31 de julio de 1992.

24 VAldÉs DAL-RE, Fernando, «Los inciertos....», ob. cit., pág. 58. 


\section{La reforma laboral de 1994 y el nuevo artículo 1.3.g) del Estatuto de los Trabajadores}

La Ley 11/1994 de 19 de mayo, en virtud de la cual se modifican determinados artículos tanto del Estatuto de los Trabajadores como del Texto Articulado de Ley de Procedimiento Laboral, y de la Ley sobre Infracciones y Sanciones en el Orden Social, viene a adicionar un nuevo apartado g) al artículo 1.3. ${ }^{\circ}$ del Estatuto, que supone un paso más, o si se prefiere un nuevo giro, en la línea marcada por la jurisprudencia. Podría parecer que en un primer momento la expansión del principio de laboralidad que había promovido el Tribunal Supremo, sobre todo a partir de 1986, se pudiera ver cortada por este nuevo artículo, que consagra la figura del transportista autónomo.

El artículo $1.3 .^{\circ}$ regula las exclusiones del ámbito de las relaciones laborales y entre ellas el párrafo g) señala:

«g) En general, todo trabajo que se efectúe en desarrollo de relación distinta de la que define el apartado 1 de este artículo.

A talas efectos se entenderá excluida del ámbito laboral la actividad de las personas prestadoras del servicio de transporte al amparo de autorizaciones administrativas de las que sean titulares, realizada mediante el correspondiente precio, con vehículos comerciales de servicio público cuya propiedad o poder directo de disposición ostenten, aun cuando dichos servicios se realicen de forma continuada para un mismo cargador o comercializador».

Dejando a un lado el primer párrafo de este apartado, dado que resulta reiterativo e innecesario ${ }^{25}$, nos debemos centrar en el segundo, el cual parece a simple vista excluir del ámbito laboral a los transportistas autónomos. Sin embargo, para poder determinar el alcance de la citada exclusión, es necesario examinar los requisitos que la misma exige al amparo de lo preceptuado en dicho párrafo:

1) La persona prestadora del servicio de transporte debe ser titular de la correspondiente autorización administrativa: este requisito implica que se vuelve a la distinción entre el mensajero urbano y el transportista profesional, puesto que parece evidente que con el término «autorización administrativa», el legislador no se está refiriendo al mero permiso de circulación que requiere todo vehículo, sino sin duda

25 Pedrajas Moreno, Abdón, «Transportistas: alcance de la exclusión de laboralidad ex artículo 1.3.g) del Estatuto de los Trabajadores», Actualidad Laboral, n. ${ }^{\circ}$ 21/22 (1995), pág. 318. 
a aquellas actividades de transporte que por su propia naturaleza, transporte de personas, lugares o dimensiones del vehículo, necesitan la pertinente tarjeta de transporte conforme a la Ley de Ordenación del Transporte Terrestre (LOTT) ${ }^{26}$. Esta autorización administrativa puede tener ámbito nacional o local ${ }^{27}$, pero lo verdaderamente relevante a los efectos que en este momento nos interesan, es que no requiere dicha autorización el transporte de mercancías en vehículos cuyo peso máximo autorizado sea igual o inferior a dos toneladas ${ }^{28}$, siendo necesaria para vehículos de tracción propia, tanto ligeros como pesados, matriculados y habilitados para circular, y que hayan superado la correspondiente inspección técnica ${ }^{29}$.

De la redacción literal del precepto se deduce no sólo que el vehículo que se utilice para el transporte debe cumplir los requisitos necesarios para disponer de autorización administrativa, sino que dicha autorización debe venir expedida a nombre del transportista en cuestión. Ahora bien: a mi entender resulta evidente que una interpretación lógica de este precepto no exige que el transportista sea de hecho titular de la tarjeta de transporte, sino que basta que utilice un vehículo que preceptivamente la requiera, puesto que una interpretación contraria estaría dejando en manos del interesado la configuración del vínculo que le une a la empresa, y simplemente incumpliendo la normativa vigente — esto es, no solicitando la correspondiente autorización a pesar de que su vehículo legalmente la requiriese- obtendría el reconocimiento del carácter laboral de su relación, lo cual deviene a todas luces absurdo ${ }^{30}$.

Por otra parte, de este primer requisito se puede extraer con claridad una primera conclusión: el artículo $1.3 .^{\circ} \mathrm{g}$ ) no resulta aplicable a la actividad de la mensajería, de forma que su ámbito de aplicación queda reducido a la actividad de transporte, y dentro de ella, únicamente a la que exija para su desempeño la correspondiente autorización administrativa.

${ }^{26}$ La regulación de las autorizaciones de transporte puede encontrarse en los arts. 90-92 de la LOTT (Ley 16/1987 de 30 de julio), 41, y 109-122 del Reglamento (R.D. 1.211/1990 de 28 de septiembre), y en la Orden de 3 de febrero de 1993.

27 Art. 91 LOTT y 111 del Reglamento.

28 Art. 41.2. ${ }^{\circ}$ c) del Reglamento.

${ }_{29}$ Un estudio sobre el régimen jurídico de las autorizaciones de transporte puede encontrarse en CARBOnell PORRAS, Eloísa, Régimen Jurídico Administrativo del transporte interurbano por carretera, Madrid, Universidad Complutense, 1993, págs. 357-378. Sobre los requisitos y clases de autorizaciones puede consultarse el Manual para el control del transporte nacional e internacional de viajeros y mercancías, Madrid, Ministerio de Obras Públicas, Transporte y Medio Ambiente, 1995.

30 En esta línea se manifiesta también el Tribunal Superior de Justicia de Cataluña, en su Sentencia de 3 de marzo de 1997. 
2) El transportista debe ser propietario del vehículo con el que presta el servicio, o cuanto menos debe ostentar un poder directo de disposición sobre el mismo.

3) El vehículo comercial utilizado debe ser de servicio público: en este sentido, y al amparo de la LOTT, habrá que distinguir entre transporte privado y público. El público es el que se lleva a cabo por cuenta ajena y mediante retribución ${ }^{31}$, mientras que el privado es el que se realiza por necesidades de desplazamiento de carácter personal o doméstico (particular), o por empresas cuya finalidad principal no es la del transporte (complementario). El transporte a su vez puede ser regular o discrecional, aunque el transporte público de mercancías siempre se considera discrecional ${ }^{32}$.

4) Dichos servicios pueden realizarse de forma continuada para un mismo cargador o comercializador: esto supone que la exclusividad en la prestación del servicio no es una característica que laboralice la relación, siempre que se cumplan el resto de los requisitos.

5) El servicio debe ser retribuido mediante precio: este último punto resulta irrelevante, puesto que es evidente que la prestación del servicio debe tener prevista una contraprestación económica, y que ésta, si estamos ante un contrato mercantil, debe ser el «precio». No obstante la denominación concreta que se dé a dicha contraprestación no es un elemento indiciario de la extralaboralidad de la relación, puesto que, como ya se ha puesto de manifiesto anteriormente, la relación laboral se configura al margen de la voluntad de las partes, y como bien apunta Pedrajas ${ }^{33}$, si existen las características propias del salario, poco importa la denominación que las partes le hayan otorgado.

\subsection{Naturaleza de la exclusión}

Resulta interesante analizar con carácter previo la naturaleza de la exclusión que se contempla en el artículo 1.3. ${ }^{\circ} \mathrm{g}$ ) del Estatuto, en el sentido de si dicha exclusión es meramente declarativa o si por el contrario es constitutiva.

En definitiva, el problema se reduce a tratar de averiguar cuál ha sido la voluntad del legislador con la inclusión de este nuevo párrafo,

\footnotetext{
31 Artículo 62.2. ${ }^{\circ}$ LOTT.

32 RazQuin Lizarraga, José Antonio, «Derecho Público del transporte por carreteras», Pamplona, Aranzadi, 1995, págs. 405 y ss.

33 Pedrajas Moreno, Abdón, ob. cit., pág. 319.
} 
algo que puede resultar a priori difícil ante el silencio total de la Exposición de Motivos de la Ley 11/1994.

Si entendemos que la exclusión es declarativa, ello supondría reconocer que en el supuesto que se contempla en la misma, es decir, en el caso del transportista autónomo, no concurren las características propias del contrato de trabajo, y que es por ello por lo que queda excluida. De esta forma el segundo párrafo del apartado g) sería una mera concreción a un supuesto específico de lo establecido en el párrafo primero, es decir, de la exclusión de laboralidad de todo trabajo que se efectúe en desarrollo de relación distinta de la que define el artículo 1.1. ${ }^{\circ}$ del Estatuto. Esto implicaría que aunque dicho apartado g) no existiera, la relación que en él se contempla no sería laboral, sino mercantil, y que el referido apartado simplemente se limita a constatar una situación fáctica.

En cambio, si entendemos que la exclusión es constitutiva, nos encontraríamos ante una situación que, aun pudiendo reunir las características propias de la relación laboral, sin embargo el legislador ha optado por excluir de este ámbito. ¿Significaría esto que de no existir este artículo $1.3 .^{\circ} . \mathrm{g}$ ) nos encontraríamos ante un contrato de trabajo? No se puede afirmar con rotundidad, puesto que habría que examinar en cada concreto caso si concurren las notas propias de la relación laboral establecidas en el artículo 1.1. ${ }^{\circ}$ del Estatuto de los Trabajadores. Sin embargo, lo que sí significaría es que cumpliéndose los requisitos señalados en el citado párrafo g), la relación quedaría sustraída del ámbito laboral, por voluntad expresa del legislador.

En mi opinión, coincidente con la doctrina mayoritaria en este punto, la exclusión debe considerarse de carácter constitutivo, sobre todo teniendo en cuenta que la línea jurisprudencial imperante hasta este momento era proclive, tal y como hemos visto, a incluir a los transportistas en el ámbito laboral, a pesar de concurrir los requisitos que se recogen en el nuevo apartado g), por no considerar suficientemente relevante, por ejemplo, el hecho de que el vehículo fuera propiedad del transportista, frente a otras notas que indicaban la laboralidad de la relación. El concluir que la exclusión es meramente declarativa supondría reconocer que en la situación planteada no concurren las notas características de la relación laboral, y que a pesar de ello la jurisprudencia la ha venido incluyendo en este ámbito en una clara infracción de ley. En cambio, al señalar que es de carácter constitutivo, estamos poniendo de manifiesto que, si bien la jurisprudencia anterior podría considerar que en dichas situaciones concurrían las características propias de una relación laboral, sin embargo en este momento el legislador modifica dicha línea jurisprudencial e incorpora una nueva disposición, excluyéndolas 
del ámbito laboral, siempre que se cumplan los requisitos exigidos, y a pesar de que puedan concurrir las notas propias de un contrato de trabajo.

\subsection{Alcance de la exclusión}

Respecto del alcance de la exclusión consagrada en el ya tan citado artículo $1.3 .^{\circ} \mathrm{g}$ ), la pregunta que se plantea es la siguiente: ¿establece dicho precepto una presunción «iuris et de iure», de forma que cumpliéndose los requisitos señalados en él, automáticamente la relación pasa a ser de carácter mercantil, o por el contrario se trata de una mera presunción «iuris tantum», es decir, admite prueba en contrario, de forma que a pesar de cumplirse todos los requisitos, podría demostrarse que la relación es laboral por concurrir sus notas características?

En este punto es necesario tener presente la respuesta que se ha dado en cuanto a la naturaleza de la exclusión. Si se ha llegado a la conclusión de que ésta es constitutiva, parece lo más lógico pensar que tenga carácter imperativo y no admita prueba en contrario. Además de ello, parece argumento contundente en favor de esta posición la mera ubicación sistemática de la misma: el párrafo $3{ }^{\circ}$ del artículo 1 del Estatuto enumera las situaciones que quedan excluidas de laboralidad, y ninguna de ellas es presunción, sino auténticas normas de carácter imperativo. Por ello, no hay razón alguna para intentar dotar al concreto punto g) de una condición distinta de la del resto de las exclusiones.

\subsection{La aplicación retroactiva del art. $1.3 .^{\circ} . g$ ) del E.T.}

Un problema que se puede plantear con la aparición de este precepto - máxime teniendo en cuenta el giro que supone con respecto a la línea tradicional- es el relativo a su aplicación con carácter retroactivo, es decir, a relaciones que nacieron antes de su entrada en vigor -el 13 de junio de 1994-, pero que siguen subsistiendo en la actualidad. No existen disposiciones transitorias en este sentido que puedan aclarar la situación, pero lo que sí se debe tener en cuenta a la hora de analizar este punto es que si hemos considerado la exclusión de laboralidad en este caso como constitutiva, ello supone que es desde el momento de su entrada en vigor cuando tal relación pasa a ser mercantil, y no antes, por lo que cualquier relación jurídica anterior de estas características debería considerarse laboral, de acuerdo con el criterio jurisprudencial imperante, siempre que concurran las notas características de la relación laboral. 
En cualquier caso la solución no es tan sencilla y habrá que analizar toda una serie de supuestos problemáticos:

$\left.1 .^{\circ}\right)$ Transportista autónomo ${ }^{34}$ que suscribe un contrato de trabajo con una empresa de transporte después de la entrada en vigor del artículo $1.3 .^{\circ} \mathrm{g}$ ): resulta evidente que en una situación como la descrita se debería aplicar la normativa vigente y que por tanto dicha relación debería configurarse con carácter mercantil, por mucho que las partes pretendan darle un carácter laboral, dado que una norma imperativa la excluye de tal ámbito.

$\left.2 .^{\circ}\right)$ Transportista autónomo que está vinculado con una empresa de transporte mediante una relación laboral, antes de la aparición del artículo $1.3 .^{\circ} \mathrm{g}$ ): dicha relación puede ostentar carácter laboral bien porque así lo decidieron en su día libremente las partes contratantes, - supuesto harto infrecuente en la práctica-, bien porque, instada la oportuna acción por parte del trabajador ante los órganos de la jurisdicción social, así ha sido reconocido por Sentencia judicial firme. En estos casos, ¿la relación se mantiene en la órbita laboral, a pesar de lo señalado en el citado precepto, o de hecho pasaría a tener carácter mercantil?

Desde la entrada en vigor de la reforma, se han venido produciendo en este punto opiniones contrapuestas ${ }^{35}$, pero la que parece predominante indica que estos trabajadores no podrán verse afectados por el nuevo precepto porque ello implicaría una aplicación retroactiva de normas limitativas de derechos, de carácter inconstitucional de acuerdo con el artículo 9.3..$^{\circ}$ de la Constitución Española. Con base también en el artículo 2.3. ${ }^{\circ}$ del Código Civil — que señala con carácter general que las leyes no tendrán efectos retroactivos salvo que dispusieren lo contrario-, se entiende que no debe darse al art. $1.3 .^{\circ} \mathrm{g}$ ) un efecto extensivo a las relaciones iniciadas con anterioridad a su entrada en vigor y que sustantivamente fueron encuadrables dentro del ámbito de laboralidad del artículo $1 .^{\circ}$ E.T. ${ }^{36}$. Esto supone que la relación hasta el momento de entrada en vigor de la reforma debe considerarse laboral, y, por tanto, son perfectamente exigibles todas las consecuencias que se deriven

${ }^{34}$ Lógicamente, en este punto y en los sucesivos, cuando nos referimos a «transportista autónomo», hacemos referencia a aquel que cumple los requisitos exigidos por el art. 1.3. $\mathrm{g}$ ).

35 Así por ejemplo, Valdés entiende que desde el momento que está reconocida una relación laboral, no es de aplicación el art. 1.3. $\mathrm{g}$ ), puesto que no estaríamos ante una actividad de servicio público, sino ante un transporte privado complementario. Vid. VALDÉs DAL-RE, Fernando, «Ley y jurisprudencia...», ob cit., pág. 38.

36 Sentencias de los T.S.J. de Castilla La Mancha de 5 de julio de 1995, y de Cantabria de 13 de marzo de 1995, entre otras. 
de tal calificación. Sin embargo, a partir de la entrada en vigor de la nueva normativa, la relación pasará a ser mercantil, en aplicación del principio «tempus regit actum», que implica que la nueva regulación se aplicará no sólo a las nuevas relaciones surgidas desde su entrada en vigor, sino también a los efectos futuros de relaciones pasadas. Con lo cual, aunque la relación originariamente fuese considerada laboral, si se plantease algún tipo de controversia en el futuro ante la jurisdicción social sobre hechos acaecidos después de dicha fecha, aquélla debería declararse incompetente para su resolución ${ }^{37}$. Esta interpretación está en perfecta consonancia con el carácter constitutivo del que hemos dotado a la exclusión de laboralidad: en realidad lo que se produce a mi modo de ver no es sino una novación de la relación, que pasa de tener carácter laboral a ser de naturaleza mercantil, por imperativo legal, operando tal novación desde la entrada en vigor de la nueva normativa, y por tanto, aplicándose únicamente «pro futuro», es decir, con efectos «ex nunc ${ }^{38}$.

3. ${ }^{\circ}$ ) Transportista autónomo que estaba vinculado con una empresa de transporte mediante un contrato mercantil de prestación de servicios, antes de la entrada en vigor del art. $1.3 .^{\circ} . \mathrm{g}$ ): en este supuesto, la relación permanecería en el ámbito mercantil, de forma que si en un momento dado se interpone demanda ante los Juzgados de lo Social éstos se deberán declarar incompetentes, en aplicación de la normativa vigente que excluye este tipo de relaciones del ámbito laboral. Una vez entra en vigor, la nueva ley se incorpora al ordenamiento jurídico, y se aplica a todas las relaciones jurídicas existentes en ese momento, salvo disposición en contrario del legislador.

4. $\left.{ }^{\circ}\right)$ Respecto de los asuntos que se encontrasen sub iudice en el momento de la entrada en vigor de la reforma de 1994, es evidente que el juzgador debe aplicar la legislación vigente al momento de interponer la demanda, por lo que en estos casos no se podría tener en cuenta la nueva normativa ${ }^{39}$.

37 Sentencia del T.S. de 23 de diciembre de 1996, y del T.S.J. de Cantabria de 12 de marzo de 1997.

${ }^{38}$ Existen interpretaciones que por el contrario entienden que estamos ante una novación extintiva y con efectos «ex tunc». Así, la Sentencia del Tribunal Superior de Justicia de Castilla y León de 31 de enero de 1995. Vid. SÁnchez Pego, Francisco Javier, «Los transportistas por cuenta ajena con vehículo propio: significación de la reforma laboral y régimen transitorio», Actualidad Laboral, 1995 (II), pág. 430.

39 Vid. Sentencia del T.S. de 12 de abril de 1996: se califica la relación como laboral, al no poder aplicar lo establecido en el artículo 1.3.g) del Estatuto, por ser la demanda de fecha anterior a su entrada en vigor. Lo mismo sucede en la Sentencia del T.S.J. de Cataluña de 3 de marzo de 1997. 


\subsection{La constitucionalidad del precepto}

Dado el criterio que utiliza el legislador para la determinación de los supuestos en los que la relación transportista-empresa de transporte queda extramuros del derecho laboral, podría plantearse su compatibilidad con los preceptos constitucionales, toda vez que el criterio utilizado podría entenderse discriminatorio. La cuestión se podría enunciar de la siguiente forma: ¿puede considerarse que el hecho de tener la tarjeta de transporte, o lo que es lo mismo, el hecho de que el vehículo supere un determinado tonelaje establecido legalmente, es criterio suficiente para poder determinar la laboralidad o no de una relación?

Independientemente de que a mi modo de ver el legislador no ha estado excesivamente acertado a la hora de optar por el criterio delimitador, es interesante constatar que el Tribunal Supremo ya ha tenido ocasión de manifestarse sobre este extremo, concretamente y por primera vez en su Sentencia de 5 de junio de $1996^{40}$. En ella señala que el legislador es competente para delimitar mediante criterios específicos la frontera entre la relación jurídica contrato de trabajo y otras figuras afines. Dichos criterios, para adecuarse al marco constitucional, deben ser coherentes con el criterio general de definición de la relación de trabajo, y por otra parte, debe existir una necesaria proporcionalidad entre el criterio escogido y el propósito o finalidad que se persigue.

Pues bien: el Tribunal Supremo entiende que el criterio de la autorización administrativa exigido a los transportistas a partir de un cierto tonelaje, es coherente en tanto en cuanto refleja la importancia del medio de transporte en el desarrollo de la actividad, que es indicativo a su vez del carácter por cuenta ajena o por cuenta propia del servicio de transporte realizado ${ }^{41}$. En definitiva, lo que viene a decir es que en el caso de transportistas que utilizan un vehículo de gran tonelaje, cuya adquisición requiere la inversión de una importante cantidad de dinero, puede razonablemente considerarse que dicho vehículo es la herramienta fundamental de su actividad, en la que el transportista asume todo el gasto, y el riesgo, con lo cual se desnaturalizan los rasgos de laboralidad, y priman los propios de una relación mercantil de arrendamiento de servicios. Por lo tanto, la justificación empleada es la misma que sirvió en su día al Tribunal para declarar el carácter laboral de la relación de los mensajeros con las empresas de transporte: en aquella

40 ARAmENDI SÁNCHEZ, Pablo, «Transportistas con vehículo propio tras la STS de 5-6-96», Social mes a mes, 1996 (18), pág. 14.

41 Así lo ha manifestado también en la Sentencia de 18 de julio de 1996. 
ocasión se sostenía que, dada la irrelevante inversión económica que implicaba la adquisición de un ciclomotor, no podía considerarse éste como elemento fundamental de la relación, sino que lo verdaderamente relevante era la aportación de trabajo personal. Ahora se aplica el mismo razonamiento a sensu contrario, para excluir de laboralidad a los transportistas que requieren tarjeta de transporte por utilizar vehículos de peso superior a dos toneladas.

Lo cierto es que en mi opinión - y a salvo de lo que pueda manifestar al respecto el Tribunal Constitucional-, la norma en cuestión se adecua perfectamente a los preceptos constitucionales, y no es discriminatoria en modo alguno, puesto que es cierto que establece una distinción entre transportistas, pero tal distinción se basa en un criterio objetivo y que a su vez viene establecido por Ley estatal ${ }^{42}$, por lo que queda excluida cualquier aplicación arbitraria de la normativa. Ahora bien, que el criterio adoptado sea objetivo y no discriminatorio, no significa en modo alguno que sea el adecuado.

\section{Conclusiones}

Llegados a este punto de la exposición, parece conveniente intentar extraer algunas conclusiones que puedan servir como premisas para el análisis de cualquier supuesto de esta índole que se nos pueda presentar en un momento dado. Así, en principio, parece que dos aspectos no deberían ofrecer duda alguna:

1. $\left.{ }^{\circ}\right)$ Los transportistas que desempeñen una actividad de servicio público a través de vehículos de su propiedad o sobre los que ostenten poder de disposición, y requieran preceptivamente disponer de una autorización administrativa de transporte para ello, no mantendrán relación laboral alguna con las empresas de transporte que los contraten para efectuar la distribución de mercancía, sino que dicha relación se mantendrá en la órbita mercantil, independientemente de que los servicios se presten o no en régimen de exclusividad. En estos supuestos no será necesario proceder a analizar si se cumplen o no los requisitos propios

42 Señala el Tribunal en las dos Sentencias citadas que cualquier modificación que en el futuro pueda adoptarse en cuanto al tonelaje mínimo necesario para que resulte preceptiva la autorización para el transporte deberá ser adoptada necesariamente por el legislador estatal, independientemente de las competencias que tengan asumidas en materia de transporte las Comunidades Autónomas. 
de una relación laboral, sino que, acreditadas las circunstancias mencionadas, ello deberá ser suficiente para decretar sin más el carácter extralaboral de la relación, y en consecuencia, la incompetencia del orden social de la jurisdicción para conocer de cualquier controversia que haya podido surgir entre las partes.

2. $\left.{ }^{\circ}\right)$ En los demás supuestos, esto es, personas que realizan labores de transporte con vehículos que no requieren autorización administrativa, habrá que analizar caso por caso si se cumplen o no las notas distintivas de la relación laboral, ya que sólo así se podrá llegar a determinar el carácter de la misma.

Esta primera diferenciación de supuestos parece en principio indiscutible, sobre la base de los argumentos que se han venido exponiendo anteriormente. Sin embargo, el Tribunal Superior de Justicia de Cataluña ha venido a sembrar la duda con un pronunciamiento a mi entender harto discutible, en su Sentencia de 17 de marzo de $1997^{43}$. Señala el Tribunal que el art. 1.3. ${ }^{\circ}$ g) del Estatuto de los Trabajadores elimina del ámbito laboral la relación de los llamados transportistas autónomos, y que la autorización administrativa es innecesaria puesto que el transporte de mercancías entregadas por una empresa para repartir entre los clientes es un servicio público, y ello es suficiente para excluirlo del ámbito laboral. No comparto en absoluto esta teoría, ya que según hemos analizado anteriormente, es precisamente la autorización administrativa la clave para distinguir entre unos y otros supuestos: no el hecho de que materialmente la tenga o no, sino la obligatoriedad o no de disponer de ella, fundamentalmente según el tonelaje del vehículo. Es la única interpretación posible, puesto que de otra forma no se entenderían las razones que han llevado al legislador a efectuar la mención a la autorización administrativa en el art. $1.3 .^{\circ} \mathrm{g}$ ).

En esta línea se manifiesta también el voto particular que contiene la referida Sentencia ${ }^{44}$, en el cual de una forma muy clara se pone de manifiesto cómo no todo vehículo comercial de servicio público precisa autorización administrativa, de forma que no se puede generalizar, sino que sólo aquellos que requieran dicha autorización por disponer de un P.M.A. superior a dos toneladas estarían excluidos del ámbito laboral,

43 Puede encontrarse un comentario de la referida Sentencia en Aranzadi Social (1997), presentación n. ${ }^{\circ} 37$, págs. 2.539-2.544, y el texto íntegro de la misma, en la citada revista, págs. $1.375-1.379$.

44 Voto particular del Ilmo. Sr. D. Ponç Feliu Llansà, Aranzadi Social (1997), págs. 1.3781.379 . 
y respecto de los restantes, será necesario analizar caso por caso si concurren o no las circunstancias propias de una relación laboral.

Aspecto muy distinto es, por supuesto, que esto sea lógico y razonable. En mi opinión, y como ya he manifestado anteriormente, no me parece acertado que lo que determine la laboralidad o no de una rotación sea en último término el tonelaje del vehículo, puesto que tan empresario autónomo puede ser quien dispone de un vehículo de dos toneladas de peso máximo autorizado, como quien dispone de uno o varios de tonelada y media, y sin embargo, el primero queda excluido «ope legis» del ámbito laboral, mientras que en el caso del segundo habría que analizar todas las características de su relación con la empresa de transporte para poder determinarlo. Sin embargo, hoy por hoy, y a la luz del art. $1.3 .^{\circ} \mathrm{g}$ ), no cabe otra interpretación posible, y la propuesta por el Tribunal Superior de Justicia de Cataluña no se ajusta a lo preceptuado legalmente.

Por último, y respecto a quienes no cumplen los requisitos para incluirse en el supuesto del art. 1.3. ${ }^{\circ} \mathrm{g}$ ), hay que distinguir entre los motoristas o mensajeros, y los repartidores con vehículos de pequeño tonelaje. Puesto que si para los segundos siempre se plantea la duda, y hay pronunciamientos para todos los gustos en función de las concretas circunstancias, respecto de los primeros, los Tribunales mantienen un criterio bastante unánime, favorable a su inserción en el ámbito laboral, basándose en el mismo argumento que se utilizó en la «Sentencia de los mensajeros», esto es, el escaso valor económico del medio de transporte, que hace que no sea éste el elemento fundamental de la relación, sino que lo verdaderamente relevante es la aportación personal del trabajador. Así lo ha manifestado en varias ocasiones el Tribunal Supremo, señalando que el carácter personal de la prestación y su ajenidad no se desvirtúan por el hecho de la aportación de un vehículo propio por el trabajador, cuando tal aportación no tiene la relevancia económica necesaria para convertir su explotación en elemento definidor y en la finalidad fundamental del contrato ${ }^{45}$.

Sin embargo, a la hora de analizar estos casos, deben tenerse siempre presentes las peculiaridades intrínsecas de esta concreta actividad de servicios, que impiden que en la mayoría de los supuestos se perciban las características propias del derecho laboral con total nitidez. Por ello, la solución adoptada por el legislador a través del art. 1.3. ${ }^{\circ} \mathrm{g}$ ) no viene a resolver la problemática existente en el sector del transporte y

45 Sentencias de 19 de noviembre de 1992, 12 de abril y 19 de noviembre de 1996 entre otras. 
mensajería respecto de la naturaleza de las relaciones que en el mismo acaecen, salvo en unos concretos casos que en la práctica no son los más numerosos. Quizás lo más acertado hubiese sido la creación de una relación laboral de carácter especial, tal y como defendían algunos ${ }^{46}$. Sin embargo, y dado que no ha sido así, en tanto no se produzca una nueva modificación legislativa en la materia, deberán ser los Tribunales quienes decidan la mayoría de las veces el carácter de la relación que se les presenta, analizando las concretas circunstancias de cada caso. En definitiva, por consiguiente, salvo para los grandes transportistas - para quienes el legislador ha sido claro y contundente - , la regulación actual no ha eliminado en modo alguno la inseguridad sobre la que, en este punto, se mueve el importante número de personas físicas y jurídicas que se dedican al mundo del transporte y la mensajería.

46 Así opina, por ejemplo, SÁNCHEZ PEGo, Francisco Javier, ob. cit., pág. 428. 